\title{
The effects of health promotion model-based educational program on self-care behaviors in patients undergoing coronary artery bypass grafting in Iran
}

\author{
Hossein Mohsenipouya ${ }^{1}$, Fereshteh Majlessi ${ }^{2}$, Abbas Rahimi Forooshani ${ }^{3}$, Rahman Ghafari ${ }^{4}$
}

${ }^{1} \mathrm{PhD}$ of Health Education and Promotion, Cardiovascular research center, Mazandaran University of Medical Sciences, Sari, Iran

${ }^{2}$ MD, Professor, Department of Health Education and Promotion, School of Public Health, Tehran University of Medical Sciences, Tehran, Iran

${ }^{3} \mathrm{PhD}$, Professor, Department of Epidemiology and Biostatistics, School of Public Health, Tehran University of Medical Sciences, Tehran, Iran

${ }^{4}$ MD, Assistant Professor, Department of Cardiology, School of Medicine, Mazandaran University of Medical Sciences, Sari, Iran

\section{Type of article: Original}

\begin{abstract}
Background and aim: Post-operative self-care behaviors, have positive effects on increase in adaptability, and reduce cardiac surgery patients' disability. The present study is carried out aimed at determining the effect of education based on a health promotion model on the patients' self-care behaviors after coronary artery bypass surgery.

Methods: This is a semi-experimental study carried out in Mazandaran (Iran) in 2016. Two hundred and twenty patients who participated in the study were selected using a simple random sampling method from a population of postoperative patients, and divided into control and experimental groups (110 patients in each) using block (AABB) randomization. Self-designed self-care questionnaires based on a health promotion model were distributed among the patients once before and three months after intervention. The data were analyzed by SPSS22, Chi-Square tests, Mann- Whitney and ANCOVA at the significance level of $\mathrm{p}<0.05$.

Results: The average score of total self-care behaviors in cardiac surgery patients was not significant between the two groups before education ( $\mathrm{p}=0.065$ ), but after training, a significant difference was observed between the two groups $(\mathrm{p}<0.001)$. The analysis of ANOVA with repeated measure indicated that following the intervention, significant difference was observed between the two groups in terms of improvement of self-care behaviors after excluding the effect of pre-test and controlling demographic and health-related characteristics.

Conclusions: Developing and implementing a training program based on the health promotion model can enhance self-care behaviors and reduce the number of admissions in patients after cardiac surgery.

Keywords: Self-care, Theoretical Model, Coronary Artery Bypass Surgery, Health education
\end{abstract}

\section{Introduction}

The common treatment for coronary artery disease is coronary artery bypass graft (1), which, as the most common surgery for coronary heart disease in the United States, was performed on more than 300,000 patients in 2001. The initial cost of this surgery is estimated to be $\$ 30,000$ for every patient (2). Coronary artery operations constitute $60 \%$ of the total 50,000 heart surgeries performed in Iran according to the Association of Iranian Heart Surgeons (3). This operation increases the chance of survival, reduces symptoms, and enhances patients' performance; however, at the same time, various physical, mental and social problems may occur after operation (4). Some of these problems may include fatigue, dyspnea, pain at the wound site, weakness, sleeplessness, loss of appetite, fear, pessimism, edema in the legs, wound dehiscence, palpitation, and constipation (5). In a study carried out by Gao et al. (2009), the

\section{Corresponding author:}

Professor Dr. Abbas Rahimi Forooshani, Department of Epidemiology and Biostatistics, School of Public Health, Tehran University of Medical Sciences, Tehran, Iran.

Tel: +98.2142933037, Fax: +98.2188989128, Email: rahimifo@tums.ac.ir

Received: March 09, 2017, Accepted: November 04, 2017, Published: January 2018

iThenticate screening: October 12, 2017, English editing: January 13, 2018, Quality control: January 15, 2018

This article has been reviewed / commented by three experts

(C) 2018 The Authors. This is an open access article under the terms of the Creative Commons Attribution-NonCommercialNoDerivs License, which permits use and distribution in any medium, provided the original work is properly cited, the use is non-commercial and no modifications or adaptations are made. 
patients' recognized health-care needs included physical, informative and social-psychological issues (6). Omari et al. (2014) found necessary information regarding caring for foot and chest ulcers, adverse drug reactions, and the amount of physical activities as the patients' most important educational needs, and concluded that meeting these needs may improve self-care behaviors (7). In another study by Schulz et al. (2011), three weeks after operation, $69 \%$ of the patients were reported to have experienced dyspnea, 39\% sleep disturbances, $39 \%$ incision pain, $47 \%$ swelling, and $18 \%$ appetite problems. Six weeks after operation, $20.6 \%$ patients experienced dyspnea, $25.7 \%$ sleep disturbances, $23 \%$ incision pain, $40 \%$ swelling, and 20\% appetite problems (8). In a study by Lie et al. (2012), two weeks after operation, the patients' symptoms and needs included anxiety and uncertainty about pain improvement, how to do physical exercises, uncertainty about medication, sleep disturbances, irritability, worrying about postoperative symptoms, and uncertainty about the ability to resume one's job. Nonetheless, four weeks after operation, the patients' symptoms decreased, however, they continued to worry about grafts' spreading, driving, and sexual inability (9). Therefore, the patients undergoing heart surgery must be properly educated on the issue and learn self-care behaviors to lengthen their lives while improving the quality of their lives, and reduce the needs for further interventions (4). Cardiac surgery patients must be properly informed of the self-care behaviors they must perform post operation, and be educated on the possible problems following the surgery, and nutrition and medication issues. Moreover, the postoperative activities and medication prescribed are so important that success of the operation is dependent on them (10). The need to educate patients about self-care behavior is emphasized by the results of recent studies indicating lack of self-care behavior in patients $(5,11,12)$. One reason why patients do not display proper self-care behaviors is that they are not fully informed of the positive effects and thus consider them to be inefficient; hence the need for training (13). Studies also show that the counseling services and nursing care delivered at the time of discharge are not efficient, and postoperative self-care behaviors are not performed properly at home (2). The important principle with regard to self-care behaviors is the patient's contribution and taking responsibility so that they can help control the symptoms (14). Self-care behaviors can help retain patients' health, increase their adaptability, and reduce patients' disability and hospital costs (15). Patients' lack of awareness of how to perform self-care is one of the reasons behind their re-hospitalizations, which can be prevented with proper training (16). Unfortunately, the patients' education is considered to be less significant in comparison with other clinical activities, and the interventions are mostly unplanned, and lack a standard instruction (4, 17). Since educational programs and consultancy services can positively influence the patients' performance and reduce their postoperative problems, the educational programs and patients' counseling regarding self-care must be carried out and pursued at home (18). In a study by Tuna et al. (18), and Akbari and Celik (2), the findings indicated the positive effect of education and consultancy services offered to the patients on enhancing their performance and decreasing their problems after discharge. The self-care-related problems already experienced by the patients emphasize the need for employment of behavior-change theories in the field since such theories can explore the factors affecting self-care, find their relationship with self-care behaviors, and explore the details, conditions, method, and timings related to these relationships (19). Pender's Health Promotion Model (HPM) is one of the allinclusive and useful methods to study self-care behaviors, which is also a framework for exploring the factors affecting these behaviors. This model consists of three fundamental components affecting health-promoting behavior: (i) individual characteristics and experiences (prior related behavior and personal factors); (ii) behaviorspecific cognitions and affect (perceived benefits of action, perceived barriers of action, perceived self-efficacy, situational influences, interpersonal influences and activity-related affect); and (iii) desirable health promotion behavior (commitment to a plan of action) (20). Although this model has been employed in many studies and has proved effective (20-25), hitherto, there has been no study carried out with regard to the efficieny of this model in improving the CABG surgery patients' self-care behaviors. Therefore, the present research aims at studying, based on the Health Promotion Model, the effect of theory-oriented educational intervention on improvement of self-care behaviors in patients after heart surgery.

\section{Material and Methods}

\subsection{Design and participants}

This semi-experimental research was conducted in Mazandaran, Iran from January to September 2015, with 220 CABG surgery patients participating. The inclusion criteria were: 1. Having spent at least 1 month after surgery, 2. No emergency conditions, 3 . No seeing or hearing, or psychological problems according to the patient records. The exclusion criteria were emergency conditions and valve surgery patients. Tehran University of Medical Sciences issued the ethical approval to conduct the study. In this research, with respect to the goal of the study, both the experimental and the control groupwere randomly selected from the population of postoperative patients. The experimental group were trained in terms of self-care behaviors. No intervention took palce in the control group, and they only participated in regular trainings. In order to determine the intervention and control groups, a list was 
prepared which included the patients who had undergone surgery at the heart center hospital of the University of Medical Sciences in Sari which is a specialized and referral hospital in the province. Then, patients who participated in the study by the use of sample size formula were selected using simple random sampling method and divided into control and experimental groups (110 patients in each) using block (AABB) randomization. During a period of three months, two hundred and twenty patients were enrolled. Having been assessed in terms of the eligibility criteria, the patients received a brief explanation about the study, and signed an informed consent.

\subsection{Instruments}

A two-section questionnaire including demographic characteristics (such as age, gender, marital status, occupation, educational level, economic and employment status; Body Mass Index (BMI), Ejection fraction (EF), history of rehospitalization, and medical information (including records of diabetes mellitus, hypertension, high cholesterol levels and smoking), and questions based on HPM constructs (97 items) to adopt self care behaviors was distributed among the patients to collect data. The second section of the researcher-made questionnaire included the following:

1) Prior related behavior: the evaluation of qualitative and quantitative scales of self care in the past (40 items in 9 sections: nutrition and diet therapy, wound care, physical activity, daily activities, sleep and rest, the removal of harmful habits, medication orders, sexual activity, and visits to the doctor).

2) Perceived self-efficacy: the perceived ability to care for the self ( 20 items, 9 sections).

3) Behavioral feelings: the subject's feelings before, during, and after the action based on the proportion of the stimulating factor in relation to the behavioral event (5 items).

4) Perceived benefits: (4 items).

5) Perceived barriers: the subject's perceptions of what hinders self care (e.g., lack of time, cost, and lack of facilities) (9 items).

6) Interpersonal influences: the subject's comments about the emotional and practical support they receive from family members and intimate friends (13 items in two sections: individual norms and social support).

7) Situational influences: includes perceiving the current options, the characteristics of the request, and the environment before enacting a special behavior (4 items).

8) Commitment to a plan of action: ( 2 items).

Each item was presented in five incremental levels. The content validity of the instrument was CVI $=0.90$ and $\mathrm{CVR}=0.84$, with the Cronbach's alpha coefficient being 0.77 for the total scale and 0.72 to 0.82 for the subscales (26).

\subsection{Data collection and intervention}

The initial data collection was done by visiting the patients at their homes. The participants of the intervention group were trained based on the results of the self-care questionnaire (26). The educational intervention was carried out over 6 weeks, one session each week. For the purpose of group support, the experimental group was divided into three educational groups, and each week, one session was held for one educational group which lasted 60 to 90 minutes. These sessions included lectures, questions and answers, group discussion, shows, educational video clips, and pamphlets for cardiac surgery patients which were offered to the patients of the experimental group free of charge. For each educational session, a specific topic (The first week: Cardiovascular patients and the process of heart surgery, Second week: How to care for surgical wounds, Third week: How to use spirometry and effective cough, Fourth week: Nutrition in patients with heart surgery, Fifth week: Physiotherapy and physical activity, and Sixth Week: Stress Management and Coping with Stress) was prepared and presented. The educational pamphlet targeted at cardiac surgery patients was based on the health promotion model, and was developed by the researchers and scientific advisors, based on the latest resources, scientific texts and the headlines of the Ministry of Health and Medical Education. These pamphlets were given to the patients in the experimental group at the end of the educational sessions. The patients were trained constantly for 3 months after intervention, and the patients in the experimental group were also instructed and consulted individually on the phone about self-care behaviors, healthpromotion behaviors, problems and barriers. Meanwhile, the content of self-care behaviors was texted to the patients. After this period, the questionnaires were once again filled with the researcher being present and the results of the two groups were compared. In order to observe ethical considerations, educational materials after the post-test were provided to the control group.

\subsection{Statistical methods}

In order to analyze the data, IBMC SPSS $\odot$ Statistics version 22 (IBMC Corp., Armonk, NY, USA) and descriptive statistics including mean and standard deviation were utilized. In addition, inferential statistics and Chi-square, $t$ test, Mann-Whitney and ANCOVA were used to assess the intervention of the experimental and control (not trained) groups. 
http://www.ephysician.ir

\subsection{Ethical Considerations}

The ethics committee at Tehran University of Medical Sciences provided ethics approval for the study, which is part of a $\mathrm{PhD}$ thesis in the field of health education and promotion at the International Campus, Tehran University of Medical Sciences, with the code IRCT2015001248742N6 (grant ID: 28217). A brief explanation of the study was given to the patients who met the inclusion criteria, and informed consent was obtained from all the participants.

\section{Results}

In this study, all of the subjects completed the study. Table 1 illustrates the patients' demographic characteristics. The patients' average age was $60.00 \pm 9.25$ in the intervention group and $60.32 \pm 8.94$ in the control group. From the 220 patients participating in the research, $143(65.45 \%)$ were men and $77(34.54 \%)$ were women. Of these, 203 $(92.27 \%)$ were married, $124(56.36 \%)$ lived in the city and $96(43.63 \%)$ in villages. In terms of income, $103(46.8 \%)$ patients earned 200 to 500 dollars.

Table 1. Characteristics, and health status of control and intervention group patients

\begin{tabular}{|c|c|c|c|c|c|c|}
\hline \multicolumn{2}{|l|}{ Characteristics } & \multicolumn{2}{|c|}{ Control $(\mathrm{n}=110)$} & \multicolumn{2}{|c|}{ Intervention $(\mathrm{n}=110)$} & \multirow[t]{2}{*}{$\mathrm{p}$-value } \\
\hline & & $\mathrm{F}$ & $\%$ & $\mathrm{~F}$ & $\%$ & \\
\hline \multirow[t]{2}{*}{ Sex } & Male & 71 & 64.54 & 72 & 65.45 & \multirow[t]{2}{*}{$0.888^{\mathrm{a}}$} \\
\hline & Female & 39 & 35.45 & 38 & 34.54 & \\
\hline \multirow[t]{3}{*}{ Marital status } & Single & 1 & 0.9 & 1 & 0.9 & \multirow[t]{3}{*}{$0.454^{b}$} \\
\hline & Married & 100 & 90.9 & 103 & 93.6 & \\
\hline & Spouse deceased & 9 & 8.2 & 6 & 5.5 & \\
\hline \multirow[t]{4}{*}{ Educational Level } & Illiterate & 21 & 19.1 & 15 & 13.6 & \multirow[t]{4}{*}{$0.837^{\mathrm{a}}$} \\
\hline & Elementary & 40 & 36.4 & 44 & 40 & \\
\hline & High school diploma & 40 & 36.4 & 40 & 36.4 & \\
\hline & Collegiate & 9 & 8.2 & 11 & 10 & \\
\hline \multirow[t]{5}{*}{ Occupation } & Employee & 4 & 3.6 & 5 & 4.5 & \multirow[t]{5}{*}{$0.380^{\mathrm{a}}$} \\
\hline & Worker & 14 & 12.7 & 14 & 12.7 & \\
\hline & Homemaker & 39 & 35.5 & 33 & 30 & \\
\hline & Retired & 36 & 32.7 & 39 & 35.5 & \\
\hline & Freelance & 17 & 15.4 & 19 & 17.3 & \\
\hline \multirow[t]{2}{*}{ Lodging } & City & 60 & 54.54 & 64 & 58.18 & \multirow[t]{2}{*}{$0.587^{\mathrm{a}}$} \\
\hline & Village & 50 & 45.45 & 46 & 41.81 & \\
\hline \multirow[t]{4}{*}{ Income (US Dollar) } & No income & 16 & 14.54 & 10 & 9.09 & \multirow[t]{4}{*}{$0.758^{\mathrm{a}}$} \\
\hline & $<200$ & 35 & 31.81 & 36 & 32.72 & \\
\hline & $200-500$ & 50 & 45.45 & 53 & 48.18 & \\
\hline & $>500$ & 9 & 8.18 & 11 & 10 & \\
\hline \multirow[t]{2}{*}{ EF } & $\leq 40 \%$ & 18 & 16.36 & 19 & 17.27 & \multirow[t]{2}{*}{$0.857^{\mathrm{a}}$} \\
\hline & $>40 \%$ & 92 & 83.63 & 91 & 82.72 & \\
\hline \multirow[t]{3}{*}{$\operatorname{BMI}^{*}\left(\mathrm{~kg} / \mathrm{m}^{2}\right)$} & $18.5-24.9$ & 24 & 21.81 & 28 & 25.45 & \multirow[t]{3}{*}{$0.645^{\mathrm{b}}$} \\
\hline & $25-29.9$ & 63 & 57.27 & 57 & 51.81 & \\
\hline & 30 and more & 22 & 20 & 25 & 22.72 & \\
\hline \multirow[t]{2}{*}{ Hypertension } & Yes & 41 & 37.27 & 36 & 32.72 & \multirow[t]{2}{*}{$0.480^{\mathrm{a}}$} \\
\hline & No & 69 & 62.72 & 74 & 67.27 & \\
\hline \multirow[t]{2}{*}{ Diabetes } & Yes & 42 & 38.18 & 47 & 42.72 & \multirow[t]{2}{*}{$0.492^{\mathrm{a}}$} \\
\hline & No & 68 & 61.81 & 63 & 57.27 & \\
\hline \multirow[t]{2}{*}{ Dyslipidemia } & Yes & 30 & 27.27 & 24 & 21.81 & \multirow[t]{2}{*}{$0.347^{\mathrm{a}}$} \\
\hline & No & 80 & 72.72 & 86 & 78.18 & \\
\hline \multirow[t]{2}{*}{ Smoking } & Yes & 22 & 20 & 18 & 16.36 & \multirow[t]{2}{*}{$0.484^{\mathrm{a}}$} \\
\hline & no & 88 & 80 & 92 & 83.63 & \\
\hline Age (years) & Mean \pm SD & 60.3 & 8.94 & 60.0 & & $0.796^{\mathrm{c}}$ \\
\hline
\end{tabular}

${ }^{\mathrm{a}}$ Chi-squared test, ${ }^{\mathrm{b}}$ Mann-whitney test, ${ }^{\mathrm{c} I n d e p e n d e n t ~ s a m p l e ~} t$-test, $\mathrm{SD}=$ Standard deviation, ${ }^{*} \mathrm{BMI}=\mathrm{Body}$ mass index

A total of, 188 patients (83.2\%) had ejection fraction over 40\%. Moreover, 120 patients (54.5\%) had BMI of 25 29.9. Of the two groups 39 (35.45\%) participants of the experimental group and 26 (23.26\%) of the control group 
were retired. In terms of education, the majority of the participants in both experimental and control groups had education levels below high school diploma, and the least percentage of the participants had academic education. The results of Chi-square and Mann-Whitney indicated that there was no significant difference between the two groups in terms of gender $(\mathrm{p}=0.88)$, marital status $(\mathrm{p}=0.45)$, geographic location $(\mathrm{p}=0.58)$, occupation $(\mathrm{p}=0.38)$, income level $(\mathrm{p}=0.75)$, education level $(\mathrm{p}=0.83)$, EF $(\mathrm{p}=0.85)$, BMI $(\mathrm{p}=0.64)$, hypertension records $(\mathrm{p}=0.48)$, diabetes $(\mathrm{p}=0.49)$, and high cholesterol $(\mathrm{p}=0.34)$ and smoking $(\mathrm{p}=0.48)$ (Table 1). To compare the mean and standard deviation of the score of the aspects of the health promotion model before and after intervention, independent $t$ test was used (Table 2). Mean and standard deviation of the score of cardiac surgery patients' self-care behaviors was $375.40 \pm 33.20$ before training, and $392.17 \pm 22.10$ after training in the experimental group. While, in the control group, it was $383.23 \pm 29.35$ before training and $378.08 \pm 23.63$ after training. The average score of selfcare behaviors was not significant between the two groups $(\mathrm{p}=0.065)$ before training; however, there was a significant difference after training $(\mathrm{p}<0.001)$. The results of Table 2 indicated that before intervention, there was no significant difference between the two groups $(\mathrm{p}>0.05)$ in terms of average score of prior related behaviors, perceived self-efficacy, behavioral feelings, perceived benefits and barriers, interpersonal and situational influences, and commitment to self-care behaviors. But after intervention, significant statistical difference was observed between the two groups in terms of the average score of the constructs $(p<0.05)$. After controlling demographic factors such as age, gender, marital status, geographic location, education level, occupation, income level, EF, BMI, and health-related factors such as blood sugar records, cholesterol, hypertension, and smoking, and after controlling their condition prior to intervention, ANCOVA was utilized in order to investigate the effect of intervention on the Health Promotion Model constructs. The results are illustrated in Table 3. As $p<0.05$ after intervention, intervention has managed to significantly change the cardiac surgery patients' self-care behaviors in prior related behavior, perceived self-efficacy, perceived benefits, perceived barriers, behavioral feelings, interpersonal influences, situational influences, and commitment to plan of action. Table 4 illustrates that there was no significant statistical difference before intervention between the two groups in terms of number of re-hospitalizations $(p=0.069)$; however, the difference was significant after intervention $(\mathrm{p}<0.001)$ so that, following the intervention, the number of rehospitalizations was fewer in the experimental group than that of the control group.

Table 2. Comparing the two groups in terms of the average score of health-promotion model constructs with respect to self-care behaviors

\begin{tabular}{|c|c|c|c|c|c|}
\hline \multirow{2}{*}{ Variable } & \multirow{2}{*}{ Group } & \multicolumn{2}{|c|}{ Before intervention } & \multicolumn{2}{|c|}{3 months after intervention } \\
\hline & & Mean & SD & Mean & SD \\
\hline \multirow[t]{2}{*}{ Prior related behavior } & Experiment & 80 & 10.31 & 84.82 & 7.33 \\
\hline & Control & 81.09 & 10.09 & 81.05 & 7.72 \\
\hline \multicolumn{2}{|l|}{$\mathrm{p}$-value } & \multicolumn{2}{|l|}{0.449} & \multicolumn{2}{|l|}{$0.001^{*}$} \\
\hline \multirow[t]{2}{*}{ Perceived Self-efficacy } & Experiment & 87 & 10.52 & 89.46 & 7.70 \\
\hline & Control & 98.10 & 10.38 & 87.07 & 7.30 \\
\hline \multicolumn{2}{|l|}{$p$-value } & \multicolumn{2}{|l|}{0.138} & \multicolumn{2}{|l|}{$0.019^{*}$} \\
\hline \multirow[t]{2}{*}{ Behavioral feelings } & Experiment & 66.76 & 12.63 & 73.30 & 9.79 \\
\hline & Control & 68.21 & 14.45 & 69.56 & 11.46 \\
\hline \multicolumn{2}{|l|}{$\mathrm{p}$-value } & \multicolumn{2}{|l|}{0.428} & \multicolumn{2}{|l|}{$0.01^{*}$} \\
\hline \multirow[t]{2}{*}{ Perceived benefits } & Experiment & 90.13 & 10.50 & 94.36 & 7.75 \\
\hline & Control & 92.04 & 9.79 & 90.22 & 8.89 \\
\hline \multicolumn{2}{|l|}{ p-value } & \multicolumn{2}{|l|}{0.165} & \multicolumn{2}{|l|}{$0.001^{*}$} \\
\hline \multirow{2}{*}{ Perceived barriers } & Experiment & 48.54 & 16.17 & 42.86 & 10.73 \\
\hline & Control & 48.06 & 16.55 & 47.59 & 11.74 \\
\hline \multicolumn{2}{|l|}{$p$-value } & \multicolumn{2}{|l|}{0.826} & \multicolumn{2}{|l|}{$0.002^{*}$} \\
\hline \multirow[t]{2}{*}{ Interpersonal influences } & Experiment & 90.32 & 9.78 & 91.14 & 6.39 \\
\hline & Control & 92.81 & 8.77 & 89.56 & 5.27 \\
\hline \multicolumn{2}{|l|}{ p-value } & \multicolumn{2}{|l|}{0.068} & \multicolumn{2}{|l|}{$0.047^{*}$} \\
\hline \multirow[t]{2}{*}{ Situational influences } & Experiment & 35.40 & 6.81 & 55 & 8.67 \\
\hline & Control & 34.22 & 7.07 & 41.31 & 8.14 \\
\hline \multicolumn{2}{|l|}{ p-value } & \multicolumn{2}{|l|}{0.208} & \multicolumn{2}{|l|}{$0.001^{*}$} \\
\hline \multirow[t]{2}{*}{ Commitment to plan of action } & Experiment & 58.62 & 11.09 & 62.36 & 8.45 \\
\hline & Control & 61.27 & 10.58 & 55.63 & 10.09 \\
\hline p-value & & 0.072 & & $0.001^{*}$ & \\
\hline
\end{tabular}


Table 3. Results of ANCOVA for investigation of the effect of intervention on Health Promotion Model constructs

\begin{tabular}{|l|l|l|}
\hline Variables & $\mathrm{F}$ & $\mathrm{p}$-value \\
\hline Prior Related Behavior & 56.71 & $<0.001^{*}$ \\
\cline { 2 - 3 } & 76.05 & $<0.001^{* *}$ \\
\hline Perceived Self-efficacy & 21.99 & $<0.001^{*}$ \\
\cline { 2 - 3 } & 22.73 & $<0.001^{* *}$ \\
\hline Behavioral feelings & 41.14 & $<0.001^{*}$ \\
\hline Perceived benefits & 13.54 & $<0.004^{* *}$ \\
\hline Perceived barriers & 51.90 & $<0.001^{*}$ \\
\cline { 2 - 3 } & 14.07 & $<0.001^{* *}$ \\
\hline Interpersonal influences & 56.70 & $<0.001^{*}$ \\
\cline { 2 - 3 } & 19.66 & $<0.001^{* *}$ \\
\hline Situational influences & 24.18 & $<0.001^{*}$ \\
\cline { 2 - 3 } & 8.90 & $<0.003^{* *}$ \\
\hline Commitment to plan of action & 64.81 & $<0.001^{*}$ \\
\cline { 2 - 3 } & 24.09 & $<0.001^{* *}$ \\
\cline { 2 - 3 } & 37.15 & $<0.001^{*}$ \\
\cline { 2 - 3 } & 21.72 & $<0.001^{* *}$ \\
\hline
\end{tabular}

*adjusted for demographic factors (Age, Sex, Marital status, Education level, Occupation, Geographic location, Income level); **adjusted for health-related factors (EF, BMI, Diabetes history, Hypertension, Dyslipidemia, and smoking)

Table 4. The number of re-hospitalizations before and after intervention in both groups

\begin{tabular}{|l|l|l|l|l|}
\hline \multirow{2}{*}{ Re-hospitalization } & \multicolumn{2}{|l|}{ Before intervention; $\mathrm{n}(\%)$} & \multicolumn{2}{l|}{ 3 months after intervention; $\mathrm{n}(\%)$} \\
\cline { 2 - 5 } & Experiment & Control & Experiment & Control \\
\hline Zero & $88(80)$ & $76(69.1)$ & $79(71.81)$ & $55(50)$ \\
\hline 1 times & $17(15.5)$ & $24(21.8)$ & $27(24.54)$ & $36(32.7)$ \\
\hline$\geq 2$ times & $5(4.5)$ & $10(9.1)$ & $4(3.63)$ & $19(17.3)$ \\
\hline p-value & 0.069 & & $<0.001$ & \\
\hline
\end{tabular}

\section{Discussion}

Many studies agree that patients need help to perform self-care, and proper training, and consultancy services can play a key role in this regard $(5,12,26-30)$. Training, counseling, and supporting services help patients to carry out self-care behaviors and ensure that they can perform these behaviors when they leave hospital. This can reduce the symptoms and the possibility of re-hospitalization $(5,11,13,18,29,31,32)$. In this research, too, educational intervention had a positive influence on reducing the number of re-hospitalizations in the experimental group, which was consistent with the results of the above studies. The present study illustrated the effect of educational intervention based on a health promotion model on increasing CABG surgery patients' self-care behaviors. Reviewing the related literature, we did not find any studies conducted on the efficiency of educational intervention based on a health promotion model on CABG surgery patients' self-care behaviors. Nevertheless, our findings were consistent with those of Cebeci et al. (11), Nirmal Kaur (10), Negarande et al. (3), and Tuna et al. (18) indicating that educational counseling programs had positive effects on the patients' performance, reduced their postoperative problems, and increased the patients' self-care abilities. Following the educational intervention, the perceived barriers of the patients' self-care behaviors in the experimental group (19.29 \pm 4.83$)$ decreased significantly in comparison with that of the control group (21.41 \pm 5.28$)$. The findings of Adams et al. (34), Karter et al. (35), and Gagliardino et al. (36) indicated that as the perceived barriers increased, the patients' self-care behaviors decreased. Hazavehei found that for every unit decrease in the perceived barriers, self-care variable increased to 0.296 (37). In a study by Riegel et al. physical limitations, debilitating symptoms, inadaptability with treatment process, unawareness, anxiety and distress, and the related illnesses were the barriers to the patients' performing of self-care (13). With these barriers, it is not surprising that the patients display poor self-care behaviors and hence a high rate of re-hospitalizations. Therefore, the claim that the researchers must focus their intervention on removing the predicted barriers to performing self-care behaviors is acceptable.

The interesting point in this study is the effect of educational intervention on the average score of perceived benefits of self-care behaviors in the experimental group. The studies of Koch et al. (38), Patino et al. (39), and Toobert (40) showed that there was a direct and significant relationship between the patients' perception of the benefits of selfcare and their pursuit of the behavior. The results of a study carried out by Shojafard et al. indicated that after 
educational intervention, the patients' self-care behaviors and their perception of the benefits of these behaviors increased in patients with heart failure (41). As a result, in order to increase the effect of educational interventions, it seems necessary to put emphasis on improving the knowledge of patients and their families with respect to the positive outcomes of self-care behaviors or reinforcing the results of performing self-care behaviors. The results of the present study also showed that educational intervention is capable of increasing the average score of intersituational influences in the experimental group after the intervention in comparison with the control group. This structure can increase or decrease the adherence to or contribution in performing health-related behaviors. This structure includes items of specified or contextual situations and conditions which can facilitate or hinder the performing of the behavior (42). The study by Ho Ay et al. aimed at empowering people with diabetes based on Pender's model, indicated that the health service providers needed to understand and follow modifiable special behaviors, and that situational influences affected empowering people with diabetes (25). The results of a study by Kuo et al. showed that situational influences were strong predicting factors for commitment to get human papilloma virus vaccination (21). In this regard, the results of our pretest showed that the majority of the patients had watched a program on TV about CABG surgery patients' self-care behaviors. The findings of the study of Dehdari et al. was consistent with ours (22). Training people to live a healthy life depends on transmitting information to them which is made possible through media. A healthy life cannot be achieved unless the media plays its role. Thus, more attention needs to be paid to the role of the media in informing the public. Each branch of the media has specific functions and effects in different situations, and choosing the suitable media is an art which can enhance the efficiency of healthy behaviors to a remarkable level.

The current study showed that in comparison with the control group, the experimental group saw a remarkable increase in terms of the average score of the interpersonal influences after the intervention. The results of the study by Dehdari et al. (22), Ho et al. (25), and Teymouri et al. (43) were consistent with the results of our study. In this research, the majority of the participants announced that their families, friends, and the doctors and hospital staff had an important role in encouraging them to carry out regular self-care behaviors. Keegan et al. reported that the family and friends of the people with spinal cord injuries had an important role in persuading them to do sports and physical activities (20). Prior related behavior is one of the recognized constructs of Pender's model which affects people's beliefs and behavior (42). The results of the current study showed that educational intervention was capable of increasing the average score of the prior related behavior in the experimental group in comparison with the control group. Kuo et al. found that the factors related to the previous vaccination behavior were strong predictors of commitment to get vaccination in the next 6 months (21). Keegan et al. concluded that the level of physical activities before injury was a predictor of the level of physical activities after injury in people with spinal cord injuries (20). The findings of Dehdari et al. (22), Wong, and Mullan (44) showed that previous behaviors predicted students' probable breakfast consumption in the future. Since the experiences of prior behaviors have direct and indirect effect on current health behaviors (20), it is necessary that the patients receive correct training in terms of self-care behaviors while in hospital so that they can obtain useful experiences to benefit from in future. The findings of the present study indicated that Behavioral feelings resulting from doing self-care activities was significant in the experimental group after intervention. The results of a study by Teymouri et al. (43) were consistent with our findings which indicate that educational intervention can have a positive and significant effect on the perceived feelings related to behavior for increasing physical activities. Thus, when the patients feel happy, peaceful, and efficient while performing the behavior, this can have more effect on their self-efficacy and commitment to do selfcare activities, and it encourages them to plan for performing the behavior and to adhere to that plan. In the present study, it was observed that, following the intervention, the experimental group displayed higher self-efficacy scores in comparison with the control group, and this difference was significant. The results of a study by Duarte et al. (45), Maeda et al. (46), and O'Neil et al. (47) were consistent with our findings which showed that self-efficacy could have an important role in controlling the illness in patients with heart failure and their self-care behaviors. Sarkar et al. investigated the relationship between self-efficacy and health conditions in patients with coronary artery disease. Their findings revealed that decrease in self-efficacy scores was accompanied with more symptoms in patients $(\mathrm{OR}=2.1, \mathrm{p}=0.001)$, more physical constraint $(\mathrm{OR}, 1.8, \mathrm{p}<0.0001)$, worse life quality $(\mathrm{OR}=1.6, \mathrm{p}<0.0001)$ and worse overall health $(\mathrm{OR}=1.9, \mathrm{p}<0.0001)$ (47). Improving self-efficacy leads to better self-management results, increases life expectancy (49), and adjusts health behaviors (50). Improving self-efficacy is linked with controlling symptoms, treatment, physical consequences, and patients' social-psychological effects (51). Therefore, with respect to the role of self-efficacy in adjusting CABG surgery patients' behaviors, increasing patients' self-efficacy must be taken into consideration while developing educational programs and counseling services. The major problems facing any research which also includes our study are incompleteness of information and records of patients. Also, regarding 
the data collected through self-report questionnaires, which may possibly have tempted the participants to present more desirable images of themselves.

\section{Conclusions}

With regard to the role of health education specialists in improving patients' health and teaching them self-care behaviors, these behaviors can be identified, and accordingly, a planned intervention can be developed to improve self-care behaviors and thus improve the quality of cardiac surgery patients' lives after operation. Altogether, the results of this study showed that educational intervention based on a health promotion model proved effective in improving self-care behaviors in cardiac surgery patients. These interventions can be helpful in convincing patients to carry out behavioral changes and adhere to food and drug regimens.

\section{Acknowledgments:}

Research budget was paid by the International Campus, Tehran University of Medical Sciences. We would like to thank the patients and their families at the Tooba Medical Center, the Heart Center Hospital of Mazandaran University of Medical Sciences, Sari, Iran. This is part of a PhD thesis in the field of health education and promotion with the code IRCT2015001248742N6 (grant ID: 28217).

\section{Conflict of Interest:}

There is no conflict of interest to be declared.

\section{Authors' contributions:}

Mohsenipouya, Majlessi conceived and supervised the study, and helped in the conception, design and interpretation of data. Shojaeizadeh participated in manuscript preparation and epidemiological work. Rahimi Froshooni helped to draft the manuscript, and performed statistical analysis. All authors read and approved the final manuscript.

\section{References:}

1) McKenzie LH, Simpson J, Stewart M. A systematic review of pre-operative predictors of post-operative depression and anxiety in individuals who have undergone coronary artery bypass graft surgery. Psychol Health Med. 2010; 15(1): 74-93. doi: 10.1080/13548500903483486. PMID: 20391226.

2) Akbari M, Celik SS. The effects of discharge training and counseling on post-discharge problems in patients undergoing coronary artery bypass graft surgery. Iranian journal of nursing and midwifery research. 2015 ; 20(4): 442-9. doi: 10.4103/1735-9066.161007.

3) Negarandeh R, Nayeri ND, Shirani F, Janani L. The impact of discharge plan upon re-admission, satisfaction with nursing care and the ability to self-care for coronary artery bypass graft surgery patients. Eur J Cardiovasc Nurs. 2012; 11(4): 460-5. doi: 10.1016/j.ejcnurse.2011.05.001. PMID: 21640653.

4) Veronovici NR, Lasiuk GC, Rempel GR, Norris CM. Discharge education to promote self-management following cardiovascular surgery: An integrative review. Eur J Cardiovasc Nurs. 2014; 13(1): 22-31. doi: 10.1177/1474515113504863. PMID: 24042728.

5) Direk F, Celik SS. Post-operative problems experienced by patients undergoing coronary artery bypass graft surgery and their self-care ability after discharge. Turkish J Thorac Cardiovasc Surg. 2012; 20(3): 530-5. doi: 10.5606/tgkdc.dergisi.2012.101.

6) Gao Fj, Yao KP, Tsai CS, Wang KY. Predictors of health care needs in discharged patients who have undergone coronary artery bypass graft surgery. Heart \& Lung: The Journal of Acute and Critical Care. 2009; 38(3): 182-91. doi: 10.1016/j.hrtlng.2008.07.006.

7) Omari F, Al - Zaru I, AL - Yousef RH. Perceived learning needs of Syrian patients postcoronary artery bypass graft surgery. J Clin Nurs. 2014; 23(11-12): 1708-17. doi: 10.1111/jocn.12319. PMID: 24175928.

8) Schulz PS, Zimmerman L, Pozehl B, Barnason S, Nieveen J. Symptom management strategies used by elderly patients after coronary artery bypass surgery. Applied Nursing Research. 2011; 24(2): 65-73. doi: 10.1016/j.apnr.2009.03.001.

9) Lie I, Bunch EH, Smeby NA, Arnesen H, Hamilton G. Patients' experiences with symptoms and needs in the early rehabilitation phase after coronary artery bypass grafting. Eur J Cardiovasc Nurs. 2012; 11(1): 1424. doi: 10.1016/j.ejcnurse.2010.09.004. PMID: 21030311.

10) Kaur N, Verma P, Rana SS. Effectiveness of planned pre-operative teaching on self-care activities for patients undergoing cardiac surgery. Nursing and Midwifery Research. 2007; 98(6): 131-2. PMID: 18179130.

11) Cebeci F, Çelik SŞ. Discharge training and counselling increase self - care ability and reduce postdischarge problems in CABG patients. Journal of clinical nursing. 2008; 17(3): 412-20. doi: 10.1111/j.13652702.2007.01952.x. 
12) Seyam S, Hiedarnia A, Tavafian S. Self-Caring Behaviors among Cardiac Patients after Coronary Artery Bypass Graft Surgery. 2011; 20(79): 31-9.

13) Riegel B, Carlson B. Facilitators and barriers to heart failure self-care. Patient education and counseling. 2002; 46(4): 287-95. PMID: 11932128.

14) Schreurs KM, Colland VT, Kuijer RG, de Ridder DT, van Elderen T. Development, content, and process evaluation of a short self-management intervention in patients with chronic diseases requiring self-care behaviours. Patient education and counseling. 2003; 51(2): 133-41. PMID: 14572942.

15) Mohammadpor A, Rahmati Sharghi N, Khosravan S, Alami A. Investigating the level of self-care and supportiv eeducative needs of patients with myocardial infarction, based on Orem's model. Journal of Research \& Health. 2013; 3(4): 489-96.

16) Mullis RL, Chapman P. Age, gender, and self-esteem differences in adolescent coping styles. The Journal of Social Psychology. 2000; 140(4): 539-41. doi: 10.1080/00224540009600494.

17) Deyirmenjian M, Karam N, Salameh P. Preoperative patient education for open-heart patients: a source of anxiety? Patient education and counseling. 2006; 62(1): 111-7. doi: 10.1016/j.pec.2005.06.014.

18) Tuna Z, Celik SS. Discharge training and counseling: Functional autonomy and post-discharge problems of elderly patients undergoing coronary artery bypass graft surgery. Turk Gogus Kalp Damar. 2014; 22(3): 570-6. doi: 10.5606/tgkdc.dergisi.2014.9623.

19) Norouzi A, Ghofranipour F, Heydarnia A, Tahmasebi R. Determinants of physical activity based on Health Promotion Model (HPM) in diabetic women of Karaj diabetic institute. Iran South Med J. 2010; 13(1): 41 51.

20) Keegan JP, Chan F, Ditchman N, Chiu CY. Predictive Ability of Pender's Health Promotion Model for Physical Activity and Exercise in People With Spinal Cord Injuries: A Hierarchical Regression Analysis. Rehabilitation Counseling Bulletin. 2012; 56(1): 34-47. doi: 10.1177/0034355212440732.

21) Kuo PF, Yeh YT, Sheu SJ, Wang TF. Factors associated with future commitment and past history of human papilloma virus vaccination among female college students in northern Taiwan. Journal of gynecologic oncology. 2014; 25(3): 188-97. doi: 10.3802/jgo.2014.25.3.188.

22) Dehdari T, Rahimi T, Aryaeian N, Gohari MR. Effect of nutrition education intervention based on Pender's Health Promotion Model in improving the frequency and nutrient intake of breakfast consumption among female Iranian students. Public health nutrition. 2014; 17(3): 657-66. doi: 10.1017/S1368980013000049.

23) Robbins LB, Pfeiffer KA, Vermeesch A, Resnicow K, You Z, An L, et al. "Girls on the Move" intervention protocol for increasing physical activity among low-active underserved urban girls: a group randomized trial. BMC public health. 2013; 13: 474. doi: 10.1186/1471-2458-13-474.

24) Seixas NS, Neitzel R, Stover B, Sheppard L, Daniell B, Edelson J, et al. A multi-component intervention to promote hearing protector use among construction workers. International journal of audiology. $2011 ; 50(1)$ : S46-56. doi: 10.3109/14992027.2010.525754.

25) Ho AYK, Berggren I, Dahlborg - Lyckhage E. Diabetes empowerment related to Pender's Health Promotion Model: A meta - synthesis. Nursing \& health sciences. 2010; 12(2): 259-67. doi: 10.1111/j.1442-2018.2010.00517.x.

26) Mohseni Pouya H, Majlessi f, Shojazadeh DS, Rahimi Foroushani A, Ghaffari R, Habibi V. Development and psychometrics of self-care assessment scale in heart surgery patients based on health promotion model. Razi Journal of Medical Sciences. 2016; 23(150): 11-9.

27) Akyol AD, Cetinkaya Y, Bakan G, Yaralı S, Akkuş S. Self - care agency and factors related to this agency among patients with hypertension. Journal of clinical nursing. 2007; 16(4): 679-87. doi: 10.1111/j.13652702.2006.01656.x.

28) Gorji H, Didehdar M, Behnaz Abasi, Janati Y, Rezaei R, Yazdani Charati J. Effectivenec of discharging plan on self-care bahaviors of patients after coronary artery bypass surgery. Indian Journal of Fundamental and Applied Life Sciences. 2014; 4(1): 364-70.

29) Siabani S, Leeder SR, Davidson PM. Barriers and facilitators to self-care in chronic heart failure: a metasynthesis of qualitative studies. Springer plus. 2013; 16( 2): 320. doi: 10.1186/2193-1801-2-320.

30) Fredericks $S$, Yau T. Educational intervention reduces complications and rehospitalizations after heart surgery. Western journal of nursing research. 2013; 35(10): 1251-65. doi: 10.1177/0193945913490081.

31) O'Brien L, McKeough C, Abbasi R. Pre - surgery education for elective cardiac surgery patients: A survey from the patient's perspective. Australian occupational therapy journal. 2013; 60(6): 404-9. doi: $10.1111 / 1440-1630.12068$. 
32) Naji H, Nikhbakht Nasrabadi A, Shaban M, Saebnia R. The effect of using Orem's model of self-care on recovery of patients with heart failure. Iranian Journal of Nursing and Midwifery Research. 2009; 14(4):174-9.

33) Hazavei SM, Sabzmakan L, Hasanzadeh A, Rabiei K, Roohafza H. The effects of an educational program based on PRECEDE model on depression levels in patients with coronary artery bypass grafting. ARYA atheroscler. 2012; 8(1): 36-42. PMID: 23056099, PMCID: PMC3448400.

34) Adams AS, Mah C, Soumerai SB, Zhang F, Barton MB, Ross-Degnan D. Barriers to self-monitoring of blood glucose among adults with diabetes in an HMO: a cross sectional study. BMC health services research. 2003; 19(3): 6. PMID: 16659642.

35) Karter AJ, Ferrara A, Darbinian JA, Ackerson LM, Selby JV. Self-monitoring of blood glucose: language and financial barriers in a managed care population with diabetes. Diabetes care. 2000; 23(4): 477-83. PMID: 10857938.

36) Gagliardino JJ, Etchegoyen G. A Model Educational Program for People With Type 2 Diabetes A cooperative Latin American implementation study (PEDNID-LA). Diabetes care. 2001; 24(6): 1001-7. PMID: 11375360.

37) Hazavehei MM, Dashti S, Moeini B, Faradmal J, Shahrabadi R, Yazdi Ah. Factors related to self-care behaviors in hypertensive individuals based on Health Belief Model. koomesh. 2015; 17(1): 37-44.

38) Koch J. The Role of Exercise in the African - American Woman with Type 2 Diabetes Mellitus: Application of the Health Belief Model. Journal of the American Academy of Nurse Practitioners. 2002; 14(3): 126-30. doi: 10.1111/j.1745-7599.2002.tb00103.x. PMID: 11924335.

39) Patino AM, Sanchez J, Eidson M, Delamater AM. Health beliefs and regimen adherence in minority adolescents with type 1 diabetes. Journal of pediatric psychology. 2005; 30(6): 503-12. doi: 10.1093/jpepsy/jsi075.

40) Toobert DJ, Hampson SE, Glasgow RE. The summary of diabetes self-care activities measure: results from 7 studies and a revised scale. Diabetes care. 2000; 23(7):943-50. doi: 10.2337/diacare.23.7.943. PMID: 10895844.

41) Shojafard J, Nadrian H, Baghiani Moghadam M, Mazlumi Mahmudabad S, Sanati H, Asgar Shahi M. Effects of an educational program on self-care behaviors and its perceived benefits and barriers in patients with Heart Failure in Tehran. Payavard Salamat. 2009; 2(4): 43-55.

42) Pender NJ, Murdaugh CL, Parsons MA. Health promotion in nursing practice. 2006.

43) Teymouri P, Niknami S, Ghofranipour F. Effects of a School-Based Intervention on the basis of Pender's health promotion model to improve physical activity among high school girls. Armaghane danesh. 2007; 12(2): 47-59.

44) Wong CL, Mullan BA. Predicting breakfast consumption: An application of the theory of planned behaviour and the investigation of past behaviour and executive function. British journal of health psychology. 2009; 14(3): 489-504. doi: 10.1348/135910708X360719.

45) Duarte-Gardea M, Burgos X, Balcazar H, Braham S. Self-efficacy for healthy eating of Hispanics participating in a lifestyle intervention (806.3). The FASEB Journal. 2014; 28(1): 806-3.

46) Maeda U, Shen BJ, Schwarz ER, Farrell KA, Mallon S. Self-efficacy mediates the associations of social support and depression with treatment adherence in heart failure patients. International journal of behavioral medicine. 2013; 20(1): 88-96. doi: 10.1007/s12529-011.

47) O’Neil A, Berk M, Davis J, Stafford L. Cardiac-self efficacy predicts adverse outcomes in coronary artery disease (CAD) patients. 2013; 5(7): 6-14. doi: 10.4236/health.2013.57A3002.

48) Sarkar U, Ali S, Whooley MA. Self-efficacy and health status in patients with coronary heart disease: findings from the heart and soul study. Psychosomatic medicine. 2007; 69(4): 306-12. doi: 10.1097/PSY.0b013e3180514d57.

49) Marks R, Allegrante JP. A review and synthesis of research evidence for self-efficacy-enhancing interventions for reducing chronic disability: implications for health education practice (part II). Health promotion practice. 2005; 6(2): 148-56. doi: 10.1177/1524839904266792.

50) Ogedegbe G, Mancuso CA, Allegrante JP, Charlson ME. Development and evaluation of a medication adherence self-efficacy scale in hypertensive African-American patients. Journal of clinical epidemiology. 2003; 56(6): 520-9. PMID: 12873646.

51) Lorig KR, Holman HR. Self-management education: history, definition, outcomes, and mechanisms. Annals of behavioral medicine. 2003; 26(1): 1-7. PMID: 12867348. 